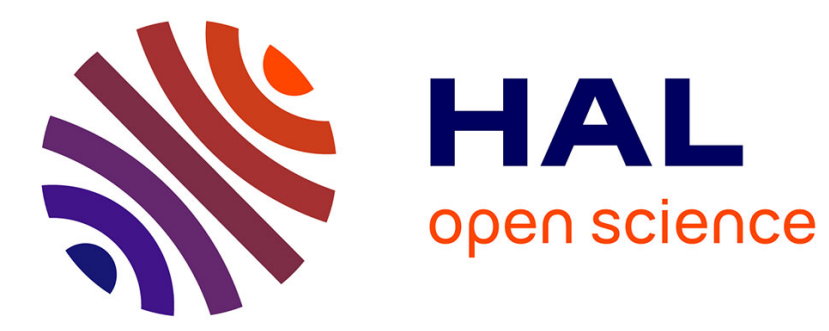

\title{
Patterns of Creative UX in immersive collaborative design
}

\author{
Stéphane Safin, Tomás Dorta, Gokce Kinayoglu
}

\section{To cite this version:}

Stéphane Safin, Tomás Dorta, Gokce Kinayoglu. Patterns of Creative UX in immersive collaborative design. 30eme conférence francophone sur l'interaction homme-machine, Oct 2018, Brest, France. 10p. hal-01899137

\section{HAL Id: hal-01899137 https://hal.science/hal-01899137}

Submitted on 19 Oct 2018

HAL is a multi-disciplinary open access archive for the deposit and dissemination of scientific research documents, whether they are published or not. The documents may come from teaching and research institutions in France or abroad, or from public or private research centers.
L'archive ouverte pluridisciplinaire HAL, est destinée au dépôt et à la diffusion de documents scientifiques de niveau recherche, publiés ou non, émanant des établissements d'enseignement et de recherche français ou étrangers, des laboratoires publics ou privés. 


\section{Patterns of Creative UX in immersive collaborative design Patterns d'UX créatives en conception collaborative}

\author{
Stéphane Safin \\ Télécom ParisTech \\ i3-CNRS - Institut interdisciplinaire \\ de l'Innovation, Paris, France \\ stephane.safin@telecom-paristech.fr
}

\author{
Tomás Dorta \\ University of Montreal \\ Design Research Laboratory \\ Hybridlab \\ Montreal, Quebec, Canada \\ tomas.dorta@umontreal.ca
}

\author{
Gôkçe Kinayoglu \\ University of Montreal \\ Design Research Laboratory \\ Hybridlab \\ Montreal, Quebec, Canada \\ gokce.kinayoglu@gmail.com
}

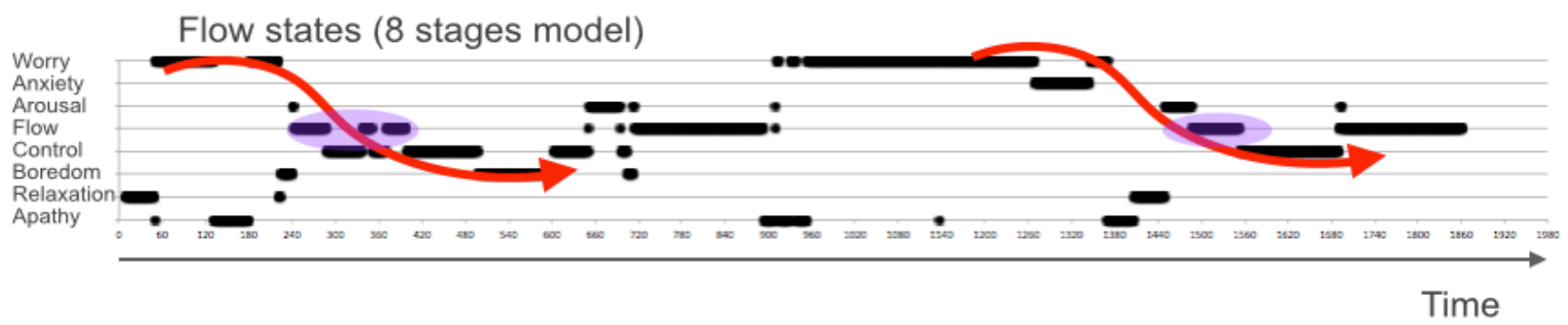

\begin{abstract}
Creativity can be studied in many ways: processes, tools, personality, etc. In this paper, we are interested in subjective emotional experience linked to creativity. People usually make rich experiences, and are more likely to be engaged in creative processes, when they face highly challenging task, and feel confident in their skills (Flow from Csikszentmihalyi [9]). On this base, our interest is to understand the dynamics of experience, how it evolves in time. We use a previously developed method, the Design Flow 2.0 [18], which allow, on a granular way, to describe the emotional states during design. In a sample of ideation sessions, during a co-design immersive studio in design pedagogy, thanks to the granular assessment, we identify patterns of creative experience linked to the creation of new and relevant ideas. Our results show two patterns, one which was expected (designers experience stress before the expression of the idea, optimal experience -flow-during its expression, and feel in control just after), and an unexpected reversed pattern (control-flow-stress), which respectively illustrate a proactive and a reactive posture in design. We discuss these results and open perspectives, about the
\end{abstract}

usage of the method to enhance co-design and to address other types of user experiences.

\section{CCS CONCEPTS}

- Human-centered computing $\rightarrow$ Interaction design $\rightarrow$ Empirical studies in interaction design; Human-centered computing $\rightarrow$ Human computer interaction (HCI) $\rightarrow$ HCI design and evaluation methods $\rightarrow$ User studies

\section{KEYWORDS}

Creativity, Experience, Design Flow, Collaborative design, Ideation

\section{RÉSUMÉ}

La créativité peut être étudiée de plusieurs façons : processus, outils, personnalité, etc. Dans cet article, nous nous intéressons à l'expérience émotionnelle subjective liée à la créativité. Les gens font généralement des expériences riches et sont plus susceptibles de s'engager dans des processus créatifs, lorsqu'ils sont confrontés à des tâches très exigeantes et qu'ils sont confiants dans leurs compétences (le Flow de Csikszentmihalyi [9]). Sur cette base, cette étude vise à comprendre la dynamique temporelle de l'expérience créative. Nous utilisons une méthode développée précédemment, le Design Flow 2.0 [18], qui permet, de manière granulaire, de décrire les états émotionnels lors de la conception. Dans un échantillon de sessions d'idéation, au cours d'un atelier pédagogique immersif de co-conception, nous identifions, grâce à la mesure granulaire, des patterns temporels d'expérience créative liés à la création d'idées nouvelles et pertinentes. Nos résultats montrent deux patterns, l'un attendu (une phase où les concepteurs ressentent du stress avant l'expression de l'idée, une phase d'expérience optimale - le 
flow, pendant l'expression de l'idée, et un sentiment de contrôle juste après), et un pattern inversé inattendu (Contrôle-flow-stress), qui illustrent respectivement une posture proactive et réactive dans la conception. Nous discutons de ces résultats et ouvrons des perspectives portant notamment sur l'usage de la méthode pour améliorer les activités de co-design et pour décrire et analyser d'autres types d'expériences utilisateurs.

\section{MOTS-CLEFS}

Créativité, user expérience, Design Flow, Conception collaborative, idéation

\section{INTRODUCTION}

Creativity is a wide notion, studied in many fields using many approaches. For Akin \& Akin [1] the general definition of creativity is: "Creativity is the process that leads to the creation of products that are novel and valuable". This definition, as many others, highlights two elements: the production of new things, and their adaptation to the context. Context should be understood in a broad sense, including evolving temporal, spatial and cultural characteristics. Thus, an idea may be uncreative (not suitable) at a specific time and become appropriate later [16].

Although many studies on creativity have traditionally focused on great artists or innovators [9], it appears essential, in light of contemporary innovation society, to address and understand, not only the "historical" creativity of great masters, but also the "psychological" dimension of creativity involved in everyday life [3].

There are many methods and ways to understand creativity (see [20] for a review). A large part of studies, rooted in differential psychology, focus on the creative personality: which personality traits enhance people's creative potential. Other models refer to the creative processes: most of them focus on reasoning processes (heuristics) associated to the emergence of new and good ideas. Design cognition studies the creative design processes and their triggers, with various models and characteristics, as well as its computersupported assistance. In addition to these approaches based on personality profiles, processes and tools, some research tries to understand creativity through energetic factors such as motives, emotions, desires, values, or preferences [8]. This study is rooted in this latter approach, and addresses the issue of the "creative experience". Experience can be considered as "the stream of actions, thoughts (e.g. interpretations, expectations, assessments, etc.), emotions, and sensory perceptions (visual, auditory, kinesthetic, etc.) occurring in a given situation at a given time, of which the actor is aware or can be made aware" [5]. In this study, we are particularly interested in the emotional and affective dimensions of the creative activities, personally experienced and subjectively perceived by people which are engaged in these activities.

To understand creative experience, it is therefore important to link the experience with creative activities. For this reason, we address creativity through the eyes of "professional creators": designers or architects for example. Although many different people may experience creative activities, designers and architects are specifically trained in all aspects related to the design and ideation process, which are central to creativity process: analogical reasoning, divergent thinking, redefining and expanding initial "wicked" design problems, etc. such elements that are commonly grouped under the term "design thinking" [7, 11].

Moreover, most studies on the creative design processes are based on an extrinsic view of the design activity by analyzing and dissecting the behavior of designers to understand its essence and parameters. In this article, we propose to complement these approaches by characterizing the design experience through an intrinsic view [5], i.e. through the eyes of designers themselves on their own activity. The proposed method is based on the concept of Flow from Csikszentmihalyi [9], according to which optimal experiences, especially the creative experiences, occur when people are engaged in activities which, on one hand, present a true challenge and, on the other hand, mobilize a high level of expertise. We also aim to assess the experience dynamically: besides identifying emotional states linked to creativity, we want to characterize how these emotional states evolve and shift in the course of the creative activity. In this study, our goal is to identify dynamic patterns of creative experience in creative design activities. For this purpose, we use a specific self-confrontation interview method for assessing creative experience in design, the Design Flow 2.0 method, that we previously designed [18], and apply it in the context a specific design studio (Augmented co-design studio at the University of Montreal). Our objectives are the following

- Validate the Design Flow 2.0 method on a sample of real creative design activities. For this purpose, our study relies on a representative long-lasting design studio (3 months) in a design department curriculum, during which we assess the creative experience of students and teacher.

- Identify dynamic patterns of creative experience in codesign. The method allowing to describe experience in a very granular way (each second) and to observe fluctuations in time, we aim to identify recurring temporal structure of creative experience. Some of these patterns are expected, thanks to our theoretical framework (see section 2.1.), but the goal of this study is also to identify unexpected patterns.

- In particular, we aim to study experience patterns linked to the expression of relevant ideas in design, i.e. ideas that had a strong impact on the design project, and which progressed through all the successive stages in the design process. Are those "good ideas" systematically accompanied by a similar experience pattern?

We filmed a sample of co-ideation activities and assessed, thanks to our method, the experiences lived by the designers during co-ideation. We identified the precise moments where the "new and pertinent" ideas are expressed and describe patterns of creative experience surrounding these moments where creative ideas emerge. 
In the paper, we first describe the Design Flow 2.0 method and its fundamentals. Then we describe the context (augmented co-design studio), the process of "good ideas" identification and the hypothesis (expected patterns). Section 4 addresses the results of the study: emotional states and experience patterns linked to the emergence of good ideas. We conclude on insight from the study about creative processes and co-design activities, study's limitations and potential applications and extensions.

\section{DESIGN FLOW 2.0: a method to assess creative experience in design}

To assess creative experience in design, we developed a new method, named Design Flow 2.0 (See [18] for full description). The method relies on retrospective selfconfrontation interviews supported by an original device. After a co-design session, designers are invited to see the video of their own activity and to use a specific simple device to "rate" their experience according to two dimensions: challenges and skills. The idea is to identify on "a very granular way" (each second) which psychological state the designer is subjectively perceiving. The method is based on Csikszentmihalyi's concept of flow [9], on Massimini and Carli's Experience Fluctuation Model [15], and on previously observed patterns of creative experience in design activities (Design Flow [14])

\section{$2.1 \quad$ Fundamentals}

Originally developed by Csikszentmihalyi [8] flow is a concept from positive psychology. It presumes that we are constantly engaged in activities involving a degree of challenge and require us to mobilize a certain level of skills. When engaged in activities with a high level of challenge mobilizing a high level of skills, we are able to get into a state of optimal experience, or flow. The challenge dimension refers to the perceived difficulty of the task, how demanding is the current activity, from the subject's own point of view. Skills refer to the perceived internal resources of the subject to complete the current task. As an illustration, if we take the task of returning a tennis ball, challenge refers to the difficulty of the ball to be returned (speed, position, spin, etc.) and the skills refers to the player's resources to hit the ball (body position, confidence, etc.). Therefore, a flow episode is likely to occur when the player is hitting the ball while having a good position (skill) to return a difficult ball (challenge).

This flow state is characterized by an altered state of consciousness, with a high level of commitment to the activity, a loss of temporal marker and a loss of awareness of the world outside the activity at hand $[8,15]$. This flow state is a fertile ground for the creative experience characterized by the emergence of new and relevant ideas. Massimini and Carli [15] identified flow episodes in daily life. They asked subjects, at random times, to answer a questionnaire on the degree of challenge of the task in which they are engaged and of mobilized skills, along with various questions relating to the state of flow (engagement, loss of notion of time, etc.). They defined eight channels of experience (based on the skill-challenge ratio in the activity, see Figure 1), that they linked with other subjective and objective variables.

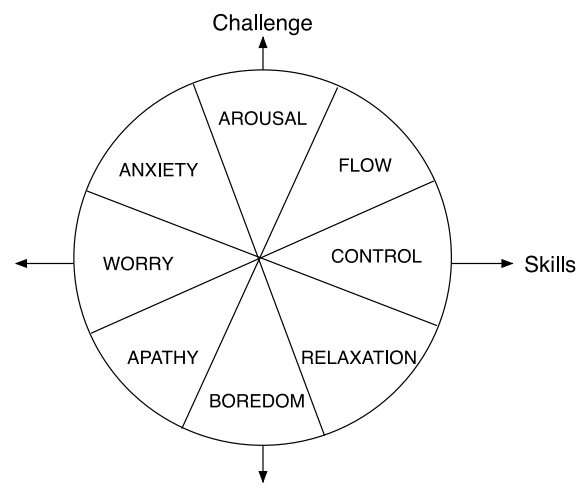

Figure 1. Skills/challenge matrix with eight emotional states (adapted from Massimini \& Carli, 1988)

They showed that in Flow state (high challenge and high skills) people reported higher level of happiness, concentration, desire to do the activity, and involvement. Relaxation, defined by low challenge and high skills, is characterized by positive mood and intrinsic motivation, as well as low cognitive investment. Apathy (low challenge and low skills) is characterized by the lowest levels of involvement, concentration and happiness. When placed in an Anxiety state, characterized by a high challenge and low skills activity, individuals do not feel able to cope with the situation, and they report high cognitive investment, low happiness, low sense of control, and difficult concentration [10].

Creativity is often associated with positive mood and affects [2]. In this model, therefore, creativity "peaks" should be associated mainly with flow state experiences: creative experience should arise when people are engaged in activities with a high level of skills combined with a high level of challenge. Based on these findings and hypothesis, and applying them to preliminary design activities, Dorta et al. [14] developed a method to assess the psychological state of designers in ideation activities. By asking designers, every 10 minutes during their activity, to assign adjectives to felt emotional states (anxiety, boredom, optimal experience, etc.), they have identified a pattern of Design Flow [14]. They found that designers' experience evolves throughout the process and they observed that designers regularly go through a recurring experience pattern, characterized by a state of stress before the generation of a relevant idea, an optimal state (called state of flow) during the proposal of the idea, and a 'sense of control' after the idea was accepted. Therefore, tension (stress) seems to be a fertile ground to the emergence of creative ideas, which delivery leads to the experience of flow.

However, the method they used suffers from two main weaknesses: (1) the method was very intrusive, asking the participant to interrupt their own activity in order to identify their psychological state and (2) even if these interruptions were done regularly, the measure suffered of 
being taken from a large time span (10 minutes). Therefore, it lacks granularity and continuity in the experience measure.

\subsection{Principles}

Therefore, and to address these limitations, we develop Design Flow 2.0 method, based on the principles of a structured auto-confrontation interview. Regularly used in ergonomics, auto-confrontation [21] is a method where a subject observes his own activity, often through a film of this activity, and expresses a subjective perspective on it, which can be a complement to the extrinsic analyses done by researchers (e.g. [4]). The advantage is that the retrospection allows to keep the co-ideation activity uninterrupted. The traces of activity (video) helps people to be engaged into their activity, allowing them to be aware of key elements of their lived experience [5]. The method proposes to designers to assess, thanks to a specific device, the perceived challenge of the activity and the perceived skills they mobilize, in a continuous and granular way (every second). The specific setting allows to reduce interview time at his minimum (the time to review the video). Based on the skills and challenges measures, we identify, each second, the psychological state (from the 8 states defined in Massimini and Carli's model [15]) the designer is currently experiencing. We use the evolution of these psychological states to identify temporal patterns of experience.

\subsection{Setting}

As mentioned, the auto-confrontation is supported with a material device in order firstly, to objectify our analyses and, secondly, to facilitate the holding of these interviews, reducing their length (auto-confrontation can be very timeconsuming).

To do this, at the end of a collaborative design session, individuals interviews are conducted. The participant settles at a console to review the video of his/her activity, while qualifying how s/he perceived two dimensions of his/her experience: the challenges (linked to the task) and skills (linked to their own confidence), the two components of flow theories on optimal experience. To this end, we developed a specific environment consisting of a preexisting hardware device, diverted for the setting (Figure 2) and an original software interface (Figure 3). The participant can control the video (play/pause) and manipulates simultaneously two sliders, one in each hand: challenge level on left hand and skills level on right hand. Our previous study has validated the possibility to rate the two dimensions simultaneously [18].

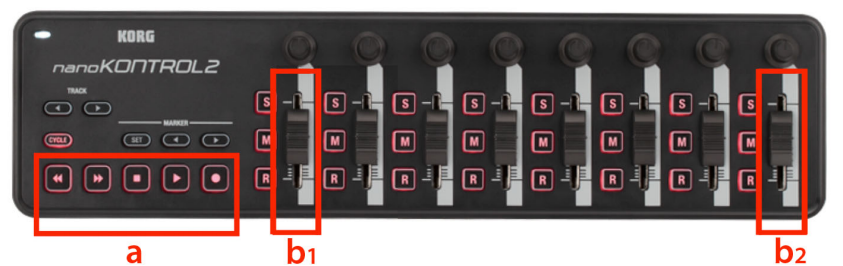

Figure 2. NanoKONTROL2 operating console: (a) the video control buttons: play, pause, rewind, etc.; (b1-2) the two sliders used, left Challenges (b1), right Skills (b2)

This device provides raw data, which is then used to qualify the psychological state of the subject at all times (anxiety, arousal, flow, relaxation, control, etc.), and to generate representations that can be analyzed by researchers to understand the dynamics of the designer's experience (Figure 3).

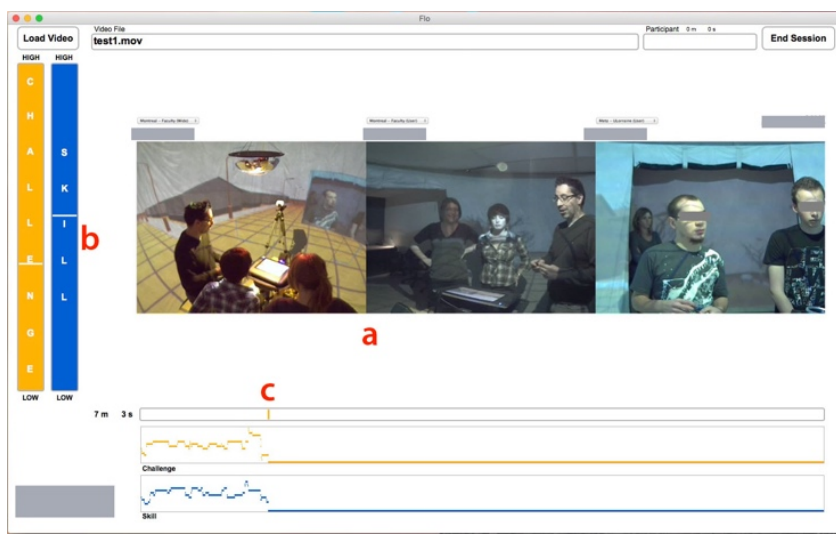

Figure 3: The interface: (a) video of activity being analyzed, (b) current state of both cursors, (c) timeline (evolution of data)

During the Design Flow 2.0 interview, the participant takes place in front of the screen, the console in hand. A researcher stands next to him/her to explain the operation of the system, to give the instruction of the experience assessment and to respond to questions asked during the auto-confrontation. This interview is entirely recorded through a screenshot of procedure, which allows researchers, afterwards, to see the ratings of the participant in connection with the video of his/her activity and his verbalizations about his judgments.

\subsection{Data analysis}

Like Massimini and Carli [15], we believe that individuals assess their skills and challenges on their own personal scales. One can imagine that some people consistently underestimate the difficulty of the tasks in which they are engaged, which does not mean that these tasks are actually simple. To compare the judgments of different individuals and different situations, removing the effects of individual scales, the scores are standardized by using classical Zscores for each dimension: (Score - mean score of the session)/Standard deviation of the scores.

At each second, the two standardized scores constitute coordinates, which are placed on a challenge/skills matrix (see Figure 1) that allows to situate the experience on one of the 8 emotional states of our model. Therefore, each second, the subject's experience is qualified on one emotional state amongst 8 . Moreover, our 8-states matrix is divided in 3 "experience zones": 
A zone of "stress" when the level of perceived challenges is high and the skills level is medium or low; Optimal area where the perception on both dimensions is high;

- An area perceived as "control" where the level of competence is high and the level of challenges is medium or low (see Figure 4).

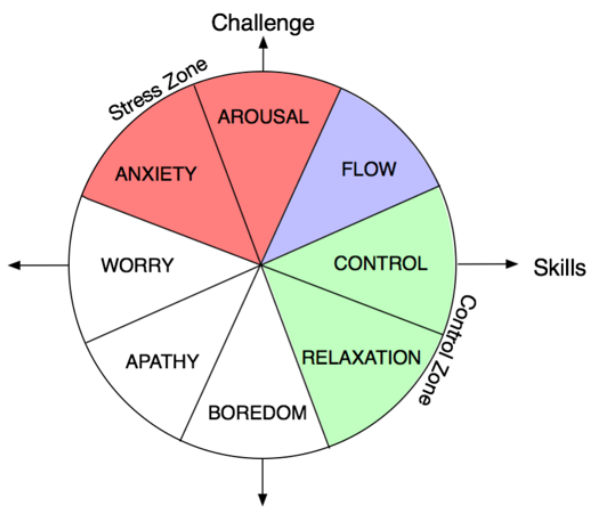

Figure 4. Skills/challenge matrix with eight emotional states and three experience zones.

On the base of the collected data, we generate timelines of emotional experience (see Figure 5), that make it possible to see the progress of the creative experience, and to compare the activities between designers.

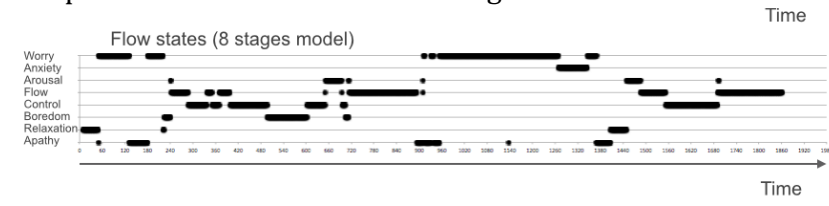

Figure 5: timeline of emotional states in a design session.

These timelines are used to visually understand the emotional rhythm of the activity, to visually and intuitively identify patterns of creative experience. According to our theoretical model, at the time of conceiving their main design concepts, we expect that designers will experience the following pattern: stressful states when tensions rise, followed by flow when identifying every good idea, then followed by control states, i.e. a release of tension because a solution was found (Figure 6). These kinds of patterns, named Design Flow patterns [14], have been identified in previous studies based on declarative interviews with designers.

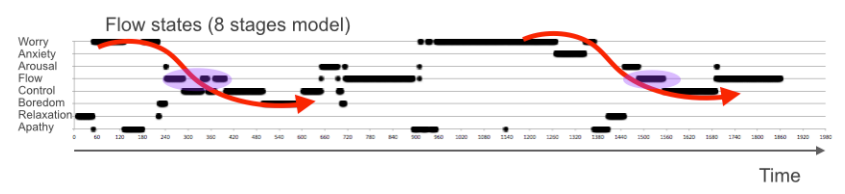

Figure 6: Expected Design flow patterns.

\section{ASSESSING CREATIVE EXPERIENCE}

\subsection{Context: Augmented co-design studio}

The study was done in the context of a co-design studio class, for third year students in industrial design at the University of Montreal. Subjects were volunteer students participating in the studio in the framework of their curriculum, and the teacher in charge of the studio. The studio includes a conventional setting: students have a semester to deliver a proposal in response to a given design problem. But it also has its own specificity:

1) The workshop is based on a co-design pedagogy: although students are individually responsible for their own design solution, simultaneous collaborative work sessions were set up, during which each student designed with a colleague and a teacher, and punctually, with professionals and students from other institutions and disciplines;

2) Specific sessions dedicated to ideation were organized on a weekly basis. These were collective sessions of co-design confined in half an hour, and specifically focused on the generation of new concepts, gathering students and the teacher in co-ideation activities;

3) These sessions took place within an original device: Hybrid Ideation Space - HIS [12]. The HIS allowed users to be immersed in their graphical representations in realscale, to interact with these representations through freehand digital drawings, and to collaborate in co-located and remote settings. Dorta et al. [13] showed that the HIS facilitates ideation, creativity and the emergence of flow episodes in designers' activity.

This setting has several advantages for our study. At first, it constitutes a real, in situ observation. The studio is part of the curriculum of the students, and they have real motivations to engage in co-design activities, which is not always guaranteed in laboratory experiments. The "ideas" we identified were part of a large-scale project, and the studio duration allowed to have an objective measure of the pertinence of the ideas: the "good ideas" are those which progress through all the successive stages in the design process, and which constitute a part of the final project. Finally, the project brief in the studio insists on innovation, which is likely to generate creative activities.

Moreover, as mentioned, the co-design sessions took place in an immersive setting. The main interest of using the HIS to support creativity is that it creates and delimits a time and space specifically dedicated to ideation (i.e. creative activity), in which designers have a limited time, in an immersive space with their teacher, to produce, represent and criticize ideas. In more classical settings, ideation activity is more distributed in time (ideation takes place outside the classroom and evaluation during the studio) and space (CAD software, drawing notebooks, disseminated sketches, etc.) and is therefore much more difficult to study.

\subsection{Creative experience assessment}

We sampled seven 30-minutes ideation activities over two different weeks of studio classes (third and fourth week, in the workshop period specifically dedicated to conceptual 
design and ideation). The Design Flow 2.0 interview method was applied just at the end of each sampled immersive coideation sessions in the HIS. Five students were involved. Three of them were interviewed once (one on session 1, two on session 2) and two students did the flow interview on both sessions. The teacher in charge of the workshop, who was also engaged in collaborative ideation process with all the students, did the flow interview for all but one of these activities, due to logistical issues.

During these Design Flow 2.0 interviews, people were asked to rate, thanks to the material setting (video and controller) their perceived creative skills (confidence in ideas, mastery of technical issues at stake, perceived own creativity, etc.) and the creative task challenge level (complexity of the concept, communication with the partner, technical or conceptual locks, etc.).

\subsection{Identification of creative ideas}

At the end of the workshop, another design teacher watched the videos of these 7 activities (lasting about 30 minutes each) to accurately identify the moments of occurrence of the key concepts, i.e. ideas that have persisted and become structural elements of the final design proposal made by students. Over the 7 observed activities, 12 key ideas have been identified, 6 authored by the student, and 6 by the teacher (see Table 1). Those key ideas are original sources of inspiration for analogical reasoning or seminal ideas for the design solution. For example, a worm body was proposed as an inspiration to be applied in the movement of a structural solution, which has later proven to be an efficient idea. This analogy has been considered as a key idea and the moment of its expression has been precisely identified in the video.

We then used Design Flow 2.0 timelines of flow interviews to identify the state of experience of the participants at the precise moment these ideas emerged, and the dynamic pattern of experience surrounding the expression of each idea.

\subsection{Hypothesis}

For each "good idea", we identify the emotional state of the idea's author and the co-designer at the moment the idea is expressed. We also identify the author's dynamic pattern of experience surrounding each idea expression. We have two main hypotheses.

1) Applying the eight-channel model of experience (Figure 1) and according to our previous findings, we expect that creative ideas occur when the designer experiences a state of flow, or into the adjacent channels (arousal and control).

2) We also expect that the appearance of these creative ideas is part of a pattern of Design Flow where the emotional states of the designer move from stressful to control through the optimal zone (see Figure 6 for expected patterns).

\section{RESULTS}

\subsection{Emotional states and idea generation}

Table 1 describes, for each key idea, its author (teacher or student) and the experience state of teacher and student at the time this idea was issued.

\begin{tabular}{|c|c|c|c|c|}
\hline $\begin{array}{c}\text { Idea } \\
\#\end{array}$ & Session & $\begin{array}{l}\text { Author } \\
\text { of idea }\end{array}$ & $\begin{array}{l}\text { Student's } \\
\text { emotional } \\
\text { state }\end{array}$ & $\begin{array}{l}\text { Teacher's } \\
\text { emotional } \\
\text { state }\end{array}$ \\
\hline 1 & $\begin{array}{l}\text { Student } 1 \\
\text { Session } 1\end{array}$ & Teacher & Flow & Flow \\
\hline 2 & \multirow{2}{*}{$\begin{array}{l}\text { Student } 2 \\
\text { Session } 1\end{array}$} & Student & Flow & - \\
\hline 3 & & Teacher & Boredom & - \\
\hline 4 & $\begin{array}{l}\text { Student } 2 \\
\text { Session } 2\end{array}$ & Teacher & Control & $\begin{array}{l}\text { Worry, } \\
\text { Apathy, } \\
\text { Boredom }\end{array}$ \\
\hline 5 & \multirow{2}{*}{$\begin{array}{l}\text { Student } 3 \\
\text { Session } 2\end{array}$} & Student & Flow & Apathy \\
\hline 6 & & Teacher & Apathy & Control \\
\hline 7 & \multirow[t]{3}{*}{$\begin{array}{l}\text { Student } 4 \\
\text { Session } 2\end{array}$} & Teacher & $\begin{array}{l}\text { Flow, } \\
\text { Arousal }\end{array}$ & Flow \\
\hline 8 & & Student & Flow & Boredom \\
\hline 9 & & Student & Flow & Boredom \\
\hline 10 & $\begin{array}{l}\text { Student } 5 \\
\text { Session } 1\end{array}$ & Teacher & Apathy & Flow \\
\hline 11 & \multirow{2}{*}{$\begin{array}{l}\text { Student } 5 \\
\text { Session } 2 \\
\end{array}$} & Student & Control & Flow \\
\hline 12 & & Student & Control & Anxiety \\
\hline
\end{tabular}

Table 1: The 12 key ideas, their author and the psychological states of the student and the teacher when the idea is expressed (author's psychological state is outlined in grey). For logistic reasons, Teacher's experiential patterns have not been recorded for one session (ideas 2 and 3 )

From this table, we can draw several conclusions. At first, we examine the experience state of each idea's author. When the issuer of the idea is the student, his psychological state falls into flow (4 occurrences - ideas 2, 5, 8 \& 9) or control (2 - ideas 11 \& 12), which corresponds to our model. When the author of the idea is the teacher, his psychological state falls into flow ( 3 - ideas $1,7 \& 10)$ or control (1 - idea 6). In one activity however (idea 4 ), he fluctuates between worry, apathy and boredom. Is seems that the vast majority of "good ideas" are expressed while the author is in flow (7 out of 11 ideas), and several (3/11) when the author is in a psychological state close to flow (control or arousal). These first results closely correspond to our hypothesis.

We also investigate the experience state of the collaborator when an idea is expressed. When the subject is not the author of an idea, it seems that there is no privileged emotional state, for both the teacher and the student: Apathy (3 occurrences), Boredom (3), Flow (2), Flow and Arousal (1), Control (1) and Anxiety (1). Therefore, it seems there is two main ways of receiving an idea: a disengaged reception, when the collaborator experiences few challenges and skills (apathy and boredom), and an engaged reception when the collaborator is in the same kinds of psychological states than the author (flow, control, arousal). In our small sample the student has a larger proportion of engaged reception $(3 / 6)$ than the teacher $(1 / 5)$. 
In synthesis, as the emotional state of flow - optimal experience - is clearly linked to the development of creative ideas for their author, the reception of the idea can be linked to optimal experience episodes but is also likely to occur in a disengaged posture. This reception posture seems related to expertise, the teacher being more often disengaged. It may also be explained by the fact that the student will be responsible of these good ideas lifecycle for the remaining weeks of the workshop, which favors an engaged reception posture.

\subsection{Creative experience patterns}

To verify our second hypothesis, relative to experience patterns, we have identified the precise moment of emergence of each key idea and displayed it on the timeline of psychological states of its author, to visually verify whether that moment was part of a particular experience pattern. We expect that the author's experience evolves from stressful states (anxiety, arousal, in orange) to flow (in blue) when the idea is expressed and then to control states (control, relaxation, in green). We sectioned-out the identified patterns to compose the following figures (Figures 7 and 8).
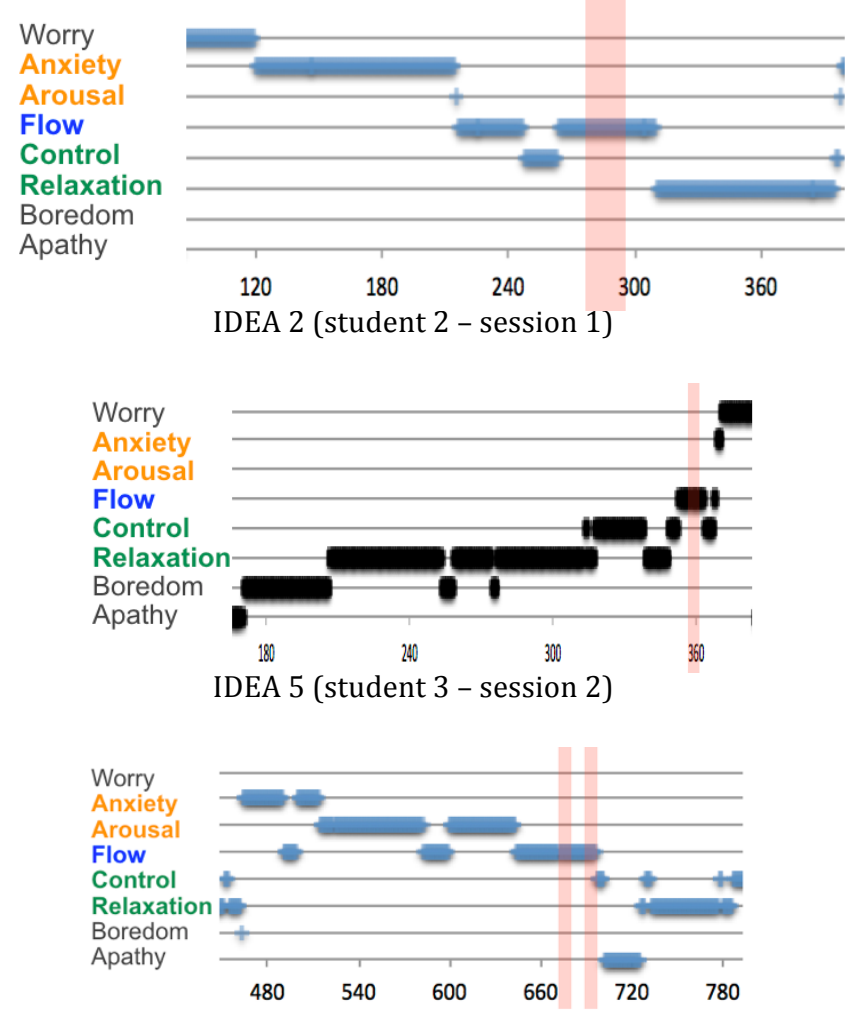

IDEAS 8 and 9 (student 4 session 2)

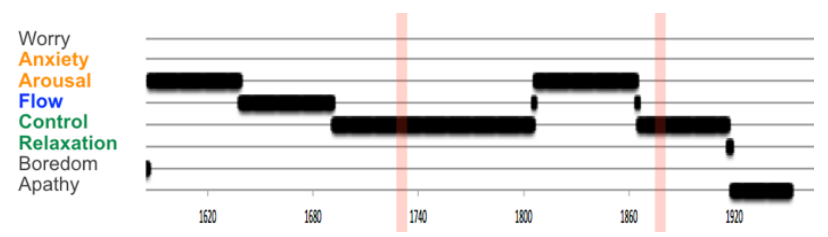

IDEAS 11 and 12 (student 5 session 2)
Figure 7: Timelines of experience patterns of students at the moment of emergence of new ideas (with author = student). Ideas emergence are identified by vertical red lines.

These timelines highlight expected patterns in 3 out of 4 cases (and 5 out of 6 ideas): a predominance of "stress states" (orange) while the group is seeking for ideas, realizing the complexity of some design issues, a moment of flow (blue), where the idea occur or an inspiring solution is found, followed by a predominance of "control states" (green) when the design concept is getting stabilized and formalized. Ideas 11 and 12, although emerging while the designer is in control, fit well in a design flow pattern; these ideas emerge after the release of tension. To illustrate this, there is tension when a given design issue is still not resolved, and a release of that tension when the designer finds a relevant solution for that issue.

For idea 5, one can observe a reversed pattern from control to flow to stress zones. Observations related to the teacheras-author are the following:

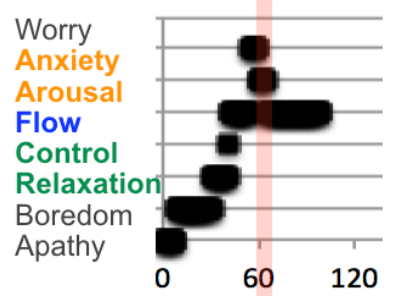

IDEA 1 (student 1 - session 1$)$. Author = teacher

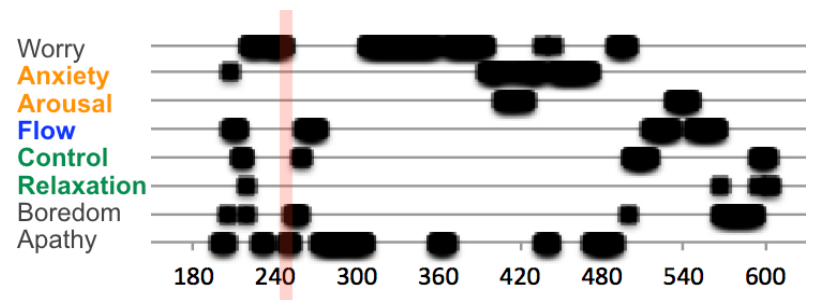

IDEA 4 (student 2 - session 2). Author = teacher

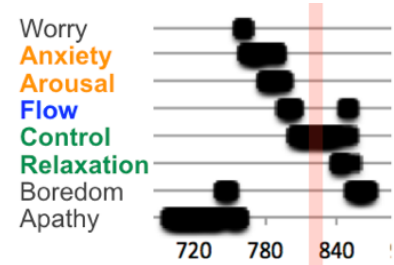

IDEA 6 (student 3 - session 2). Author = teacher

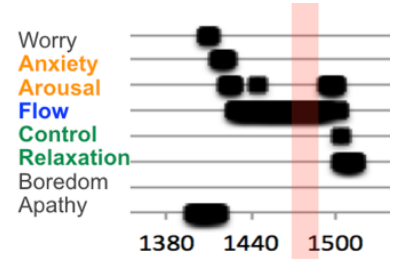

IDEA 7 (student 4 - session 2). Author = teacher 


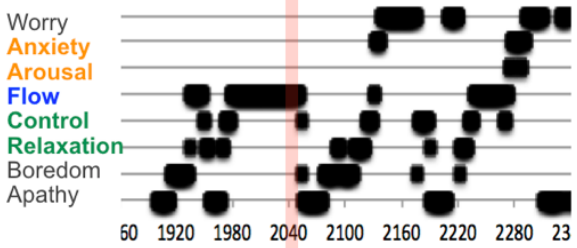

IDEA 10 (student 5 - session 1$)$. Author $=$ teacher

\section{Figure 8: Experience patterns of the teacher at the time of emergence of new ideas (with author $=$ teacher). Ideas emergence are identified by vertical red lines.}

Teacher experience patterns appear to be more random and are shorter than those of the students. Two of these patterns (ideas 6 and 7) fit into our theoretical model. One is inversed (idea 1), from control to stress, as observed with a student (idea 5). The other two ideas do not fit in clearly identifiable patterns. Idea 10 is nevertheless found during of a flow episode, yet not preceded by a stress episode and carrying a more upward (inversed) overall structure.

Although we can observe some variations, which are inevitable when calling upon one's subjectivity, most of the observed data fits well with our theoretical assumptions and our hypothesis: creative ideas appear to emerge during episodes of optimal experience, primarily as part of experience patterns starting with episodes of stress, then optimal experience and control.

In other words, the creative episodes occur when the challenge is high, causing a tension to the designer. As s/he finds a solution to resolve the challenge, $s /$ he feels that his skill level increases. When the "good or relevant idea" is expressed, challenge and skills are both high, which corresponds to the flow state. Just afterwards, the challenge diminishes, as the solution has been found, moving the designer to a state of control.

The other pattern, observed less frequently, the upward inverted pattern, can be explained this way: the designers are in a situation where they feel confident (control zone). As they move forward, more complex problems emerge (increased challenge), which moves the experience to the flow state, during which a creative idea emerges, solving the problem. Following this, the designer's being faced with new challenges generated by the unexpected ideas, his/her confidence may decrease (stress episode), although this stress does not appear in idea 10 noted above.

Our hypothesis is that the former scenario describes proactive design: the anticipated problem causes a tension that its solution decreases. In the second scenario, the design was more reactive: the problem to be solved emerges during the activity and it is directly solved by a creative idea, which bring the design at a new level of difficulty, increasing the uncertainty, which can be stressful.

It should be noted that these observations can also be interpreted in light of the level of experience of the designer: the expert designer (the teacher) experience less stress episodes following a segment of reactive design: for him a creative solution to an emerging problem does not result in a feeling of uncertainty about his skills. We see this quite clearly in the ideas 10 and 1 where stress episodes are very short.

\section{CONCLUSIONS}

This paper uses the Design Flow 2.0 method [18] in order to tackle with psychological states of designers during the ideation. The method is based on a novel form of selfconfrontation interview instrumented by a material device and an original software. It provides a continuous measure of the challenge (linked to the task) and the skills (linked to the subject) levels perceived and experienced by the designer during his/her activity. Using the 8-channel model of the Experience Fluctuation Model [15], we can determine, at each moment of the activity, the psychological state of the subject, and see, thanks to the continuous measure, its fluctuation. This allows us to identify temporal patterns of creative experience.

This study aims at identifying patterns of creative experience in design. For this purpose, in the context of a co-design augmented studio, we used the method to characterize experience of the student and the teacher after a sample of collaborative ideation activities. Retrospectively, we identified inside the ideation sessions, the moments of emergence of "good ideas", i.e. ideas that have been important for the project in the whole studio. We identified 12 ideas, authored by the student or the teacher. According to our theoretical model, based on the notion of Flow [9] and previous studies about Design Flow [14], we expected that the good idea emerge during a flow experience state, preceded by states of anxiety or arousal, and followed by states of control or relaxation.

In the analysis of creative experience psychological states, we observed that a vast majority of ideas arise when their author is in a flow state, and a minority when the author is close to flow state. This observation leads to the conclusion that, inside ideation activities, creativity is linked to micro episodes of optimal experience. Moreover, we observe two postures for the collaborator: as an engaged receptor (flow state of experience) or as a disengaged receptor (apathy). In our dynamic analysis of creative experience, we identified experience fluctuation patterns. About $2 / 3$ of these patterns are coherent with our model (stress-flowcontrol) and we identified a reversed pattern for several ideas (control-flow-stress). It seems that it illustrates two ways of problem solving in design: a proactive posture, where ideas are expected and their expression releases tension, and a reactive posture, where unexpected good ideas suddenly raises the tasks challenge. These experience patterns seem to be linked with expertise, which is still to be investigated deeper.

This first extensive study of creative experience patterns has several scientific implications. It validates and extend knowledge about creativity in the flow field, like [9] and [15], and addresses this question in the specific context of creative design. The Design Flow 2.0 method is a new way of measuring the experience, which complement previous studies and methods. It relies on subjective measures (perceived stress and challenge), which are objectified in 
psychological states, and standardized for each subject, allowing comparison between personal experiences. It also allows to apprehend the dynamic dimension of experience, which evolves through the activity, constituting an original approach to User Experience. Our study, in the field of ideation, shows that for designers, creativity is indeed linked to flow episodes, and these episodes are part of specific patterns (stress - flow - control or control - flow stress). Creativity is a dynamic process relying on tensions [17]: stress experience triggers idea generation, which generate optimal creative experiences. Our study also reproduces some results obtained by Dorta et al. [14] about the existence of specific patterns in ideation, but addressing them on a different scale, and extending them to other patterns.

On a practical point of view, our study shows that there are commonalities in the experience of creativity when designers are exposed to pertinent ideas, being in a proactive or reactive posture. Therefore, knowing experience patterns could help to develop new co-design methods: by being aware of their own experiential dynamics, designers should be able to identify creative moments and "good ideas", being more efficient in design. It may also be possible for them to identify engaged and disengaged postures in design, enhancing collaborative processes.

Another practical implication would be to help designers and especially students - to engage in reflexive and introspection activities about their own ways of designing. Reflexivity is a crucial competence but is still hard to teach [6]. Relying on experience patterns may help designers to understand the way they apprehend a design process, enhancing reflection about action and reflection in action [19].

Finally, as the Design Flow 2.0. method has proven to be efficient in identifying experience patterns in creativity, it could be extended to other activities. One of the main possibility is to use this method to assess User Experience during an interaction session (user test). By making an instrumented self-confrontation interview after a user test or an in-site interactive activities, we may be able to identify patterns of optimal interaction experience which may be linked to interface and device features. In complement to other measure (satisfaction questionnaires, usability testing, eye-tracking enquiries, etc.) it may help to address usability problems (disengaged postures) and pleasant features (flow) in order to optimize interfaces, but also and above all to measure and objectify user experience, which is still an important issue in HCI.

\section{LIMITS AND FUTURE WORK}

This study is a first exploration of the pertinence of the design Flow 2.0 method, and of the identification of patterns of creative experience. It has obviously several limitations. -Due to the real activity setting (design studio in a curriculum), the number of subjects is limited, and the subjects have specific characteristics, which may have an influence on the creative patterns: they are students (novice designers), co-designing with an expert designer, in a specific teacher-student relation. Other settings, in professional design activities, have to be studied.

- Some data are missing, due to logistical constraints.

- The Hybrid Ideation Space, in which activities took place, may have had an influence on creative experience. Results from this study have to be compared to non-immersive codesign activities.

Therefore, the results of this study have to be taken as a first exploration of dynamic micro-patterns in creative activities. They are nevertheless encouraging.

In future works, we will complement this exploration by an extensive use of the method, with the following objectives:

- At first, to gain a more exhaustive knowledge of creative experience, we need to validate the method on a larger scale, and to use it in other co-design activities contexts (non-immersive ideation, professional context, ideation with non-designer stakeholders users, citizens - etc.)

- Secondly, we need to gain a better understanding of the nature of experience identified in the creative patterns. For this purpose, measured patterns could be confronted to other types of experience data: more conventional retrospective interviews, stress questionnaires, physiological measures, to gain a qualitative understanding of creative experience.

- Thirdly, we need to extend the identification of patterns: is there others patterns? What are the patterns linked to the expression of "less good ideas"? We also plan to have a statistical bottom-up approach for pattern detection, complementary to our visual topdown approach (guided by our theoretical model) presented here.

- Fourthly, we will explore more intensively creative experience determinants. For this purpose, we will use the method to characterize the experiential processes in various conditions: representational tools, types of design, levels of expertise, etc. We also want to explore pattern of creative experience on other publics: other stakeholders of design projects (engineers, ergonomists, etc.) and users/citizens engaged in coideation activities. And we will link it to other facets of design: design process, use of external representation, quality of collaboration, etc.

- Finally, we have to engage more deeply in the identification of collective dynamics of creative experience. For this purpose, we will cross data from different designers and stakeholders engaged in the same ideation process to identify potential patterns characteristic of collective ideation, and how individual patterns co-evolve.

\section{ACKNOWLEDGMENTS}

This research was supported by the Insight Grants program from the Social Sciences and Humanities Research Council of Canada (SSHRC) (Grant number 90803). 


\section{REFERENCES}

[1] Akin, Ö., and Akin, C. (1998). On the process of creativity in puzzles, inventions, and designs. Automation in Construction, 7 123-138.

[2] Baas, M., De Dreu, C. K. W., \& Nijstad, B. A. (2008). A metaanalysis of 25 years of mood-creativity research: Hedonic tone, activation, or regulatory focus? Psychological Bulletin, 134(6), 779-806.

[3] Boden, M. A. (2004). The creative mind myths and mechanisms. London; New York: Routledge.

[4] Boubée, N. (2011). La méthode de l'autoconfrontation : une méthode bien adaptée à l'investigation de l'activité de recherche d'information? Études de communication, 35(2), 47-60.

[5] Cahour, B., Salembier, P. \& Zouinar (2016) M. Analysing the lived experience of the activity. Le Travail Humain. pp. 259-284

[6] Chaubet, P. (2010). Saisir la réflexion pour mieux former à une pratique réflexive : d'un modèle théorique à son opérationalisation. Éducation et francophonie, 38(2), 60-77.

[7] Cross, N. (2011). Design thinking: Understanding how designers think and work. New York : Berg

[8] Csikszentmihalyi, M. (1988). Motivation and creativity: Toward a synthesis of structural and energistic approaches to cognition. New Ideas in Psychology, 6(2), 159-176.

[9] Csikszentmihalyi, M. (1997). Creativity: Flow and the psychology of discovery and invention. New York: Harper Collins.

[10] Delle Fave, A., Massimini, F., \& Bassi, M. (2011). Psychological Selection and Optimal Experience Across Cultures (Vol. 2). Dordrecht: Springer Netherlands.

[11] Dorst, K. \& Cross, N. (2001). Creativity in the design process: coevolution of problem-solution. Design Studies, 22(5), 425-437.

[12] Dorta, T. (2007). Augmented Sketches and Models: The Hybrid Ideation Space as a Cognitive Artifact for Conceptual Design. In De Paoli, G., Zreik, K. et Beheshti, R. (Eds.). Digital Thinking in Architecture, Civil Engineering, Archaeology, Urban Planning and
Design: Finding the Ways, EuropIA 11. Montréal, September 2007, pp. 251-264.

[13] Dorta, T., Kalay, Y., Lesage, A., \& Pérez, E. (2011). Comparing immersion in collaborative ideation through design conversations, workload and experience. In Integration through Computation (pp. 216-225).

[14] Dorta, T., Pérez, E., \& Lesage, A. (2008). The ideation gap: Hybrid tools, design flow and practice. Design Studies, 29(2), 121-141.

[15] Massimini, F. \& Carli, M. (1988). The systematic assessment of flow in daily experience. In Csikszentmihalyi, M. and Csikszentmihalyi, I. S. (Eds). Optimal experience: Psychological studies of flow in consciousness. New York: Cambridge University Press, 266-287.

[16] McDonnell, J. (2014). Sticky Square Plates Among Other Things: Some observations from a study of long-term creative collaboration. Unpublished paper at COOP 2014 Workshop 5: Collective creativity: collaborative processes in new sociotechnical environments. Nice, May 2012

[17] Mougenot, C. Détienne, F., Pennington, M., Baker, M., Corvin, T., Veyrier, Arai, K. \& Huron, S. (2017). Tensions in Creativity Workshops. Proceedings of ECCE 2017: 93-100

[18] Safin, S. Dorta, T., Pierini, D., Kinayoglu, G. \& Lesage, A. (2016). Design Flow 2.0, assessing experience during ideation with increased granularity: A proposed method. Design Studies, vol. 47, pp. 23-46.

[19] Schön, D.-A. (1983). The reflective practitioner : how professionals think in action, New-York : Basic books.

[20] Sternberg, R. J. (2006). The nature of creativity. Creativity research journal, 18(1), 87-98.

[21] Theureau, J. (2010). Les entretiens d'autoconfrontation et de remise en situation par les traces matérielles et le programme de recherche " cours d'action ", Revue d'anthropologie des connaissances $2010 / 2\left(\right.$ Vol $\left.4, n^{\circ} 2\right), 287-322$. 